\title{
A Frequency Compensation Algorithm of Four-Wheel Coherence Random Road
}

\author{
Jun Feng, ${ }^{1}$ Xinjie Zhang, ${ }^{1,2,3}$ Konghui Guo, ${ }^{1,2}$ Fangwu Ma, ${ }^{3}$ and Hamid Reza Karimi ${ }^{4}$ \\ ${ }^{1}$ State Key Laboratory of Automotive Simulation and Control, Jilin University, Changchun, Jilin 130022, China \\ ${ }^{2}$ State Key Laboratory of Advanced Design and Manufacture for Vehicle Body, Hunan University, Changsha, Hunan 410082, China \\ ${ }^{3}$ Zhejiang Geely Automobile Research Institute Co. Ltd., Hangzhou 311228, China \\ ${ }^{4}$ Department of Engineering, Faculty of Engineering and Science, University of Agder, 4898 Grimstad, Norway
}

Correspondence should be addressed to Xinjie Zhang; xjzhang5885@gmail.com

Received 28 July 2013; Revised 15 August 2013; Accepted 15 August 2013

Academic Editor: Hui Zhang

Copyright (c) 2013 Jun Feng et al. This is an open access article distributed under the Creative Commons Attribution License, which permits unrestricted use, distribution, and reproduction in any medium, provided the original work is properly cited.

\begin{abstract}
The road surface roughness is the main source of kinematic excitation of a moving vehicle, which has an important influence on vehicle performance. In recent decades, random road models have been widely studied, and a four-wheel random road time domain model is usually generated based on the correlation of the four-wheel input, in which a coherence function is used to describe the coherence of the road input between the left and right wheels usually. However, during our research, there are some conditions that show that the road PSD (power spectral density) of one wheel is smaller than the other one on the same axle. Actually, it is caused by the uncorrelation between the left- and right-wheel road surface roughness. Hence, a frequency compensation algorithm is proposed to correct the deviation of the PSD of the road input between two wheels on the same axle, and it is installed in a 7-DOF vehicle dynamic study. The simulation result demonstrates the applicability of the proposed algorithm such that two-wheel road input deviation compensation has an important influence on vehicle performances, and it can be used for a control system installed in the vehicle to compensate road roughness for damper tuning in the future.
\end{abstract}

\section{Introduction}

The road surface roughness is the main source of kinematic excitation of a moving vehicle, which has an important influence on ride comfort, ride safety, vehicle maneuverability, driver's and occupants' comfort, and vehicle dynamic load [1-3]. Measurements of road surface roughness data are preferably done with laser/inertial high-speed profilometers, and modern laser/inertial road profilometers can record several parallel profiles simultaneously typically [4]. However, they are very expensive, inconvenient to use, susceptible to external factors, and so forth. And at the same period, the road surface roughness models have been widely investigated and applied in vehicle dynamics research. An accurate driving dynamics simulation of a vehicle on a road section is only possible if these input models are accurate themselves [5], and scholars have been focusing on the random road surface excitation simulation and reconstruction. The road surface roughness, as a stochastic process, is generally described by a PSD (power spectral density) function in a frequency domain, and, in engineering practice, it is regarded as a zero-mean stationary (or isotropic) and ergodic Gaussian process. In 1970s, the PSD function was used by Whitehouse [6] and Shinozuka [7] to investigate the road roughness. In 1993, Cebon [8] proposed a method based on the IFFT (Inverse Fast Fourier Transform) to discretize PSD which is a simple, fast, and convenient tool for generating road surfaces [2, 9]. In 1993, Grigoriu [10] proposed a method based on the harmony superposition to simulate stationary random processes. The harmony superposition method has an exact theory foundation and is suitable for arbitrarily stated spectral features. But it is rather time consuming and has an increasing demand on computer storage as a large set of trigonometric terms has to be calculated in a simulation procedure. In 1995, the contemporary international standard ISO 8608 [11] dealt with road roughness assumption, due to classification of roads into different classes according to their unevenness, equal intensity of road unevenness in the whole 
range of wavelengths, and a general form of the fitted PSD was given. A method based on linear filtering (auto-regressive and moving average methods or ARMA modelling) was proposed by Yoshimura in 1998 [12], which has a smaller calculation, and a faster simulation speed, but its precision is not very well. Bogsjö [13], in 2007, summarized different stochastic models of parallel road tracks and evaluated their accuracy by comparing the difference of the measured parallel tracks and the synthetic parallel tracks. In the same year, Ambrož proposed a system for measuring road section parameters that can be used in driving dynamics simulations. In 2012, Pazooki et al. [14] developed a comprehensive offroad vehicle ride dynamics model considering a random roughness model of the two parallel tracks. Hassan and Evans [15] collected the road longitudinal profile data of a car and truck wheel tracks and then investigated the differences of their surface roughness characteristics, which showed that the HATI (heavy articulated truck index) lane average values of a truck wheel tracks are higher than car wheel tracks. Three new road profile models [16] are proposed by Bogsjö et al. in 2012, which were compared with the classical road surface road model, and five different models were fitted to eight measured road surfaces and their accuracy and efficiency were studied.

Generally, for some researches and publications about random road surface reconstruction, a single-wheel road time domain model is established via the inverse Fourier transform, and a four-wheel road time domain model is generated based on the correlation of the four-wheel input, in which there is a time delay between the front and rear axle and the space is correlated between the left and right wheel is [17]. However, during our research, there are some conditions show that the road roughness amplitude and the road PSD of one wheel is smaller than the other one on the same axle, in other words, there is a deviation between two tracks on the same axle. Also, in 1980s, Heath $[18,19]$ pointed out that the method used for the calculation of the crossspectrum from experimental sampled data is inaccurate at high wavenumbers. Pazooki et al. [14] considered the uncorrelated component between the left and right wheels when working on modeling and validation of an off-road vehicle ride dynamics. In fact, the deviation between two tracks on the same axle has an important influence on vehicle performances. Hence, the deviation for two-wheel road input and its influence on a vehicle dynamics behavior is undertaken in this paper, and a PSD frequency compensation algorithm is proposed to improve the accuracy of the road input reconstruction.

In this paper, single-wheel and a four-wheel road time domain model is established via the Inverse Fourier Transform, and the deviation between the two wheels road PSDs on the same axle is studied firstly. Secondly, a road frequency compensation algorithm is proposed to correct the deviation of the two-wheel road PSDs on the same axle and it is installed in a road time domain model, and then it is studied via simulation and compared with ISO 8608. Finally, the road frequency compensation algorithm is applied on a 7-DOF vehicle dynamic study.

\section{Power Spectral Density of the Road Surface Roughness}

The road surface roughness is usually described in terms of the PSD of the road displacement amplitudes [20-22], and the road spectral density depends on the road itself (roughness and wave number/distribution). According to ISO 8608, road roughness level is classified from $\mathrm{A}$ to $\mathrm{H}$, and a general form of the fitted PSD is given as follows:

$$
G_{q}(n)=G_{q}\left(n_{0}\right) \cdot\left(\frac{n}{n_{0}}\right)^{-W}
$$

where $n$ is the spatial frequency $\left(\mathrm{m}^{-1}\right), n_{0}$ is the reference spatial frequency $\left(n_{0}=0.1 \mathrm{~m}^{-1}\right), G_{q}(n)$ is the spatial PSD $\left(\mathrm{m}^{2} / \mathrm{m}^{-1}\right), G_{q}\left(n_{0}\right)$ is the spatial PSD at the reference spatial frequency $\left(\mathrm{m}^{2} / \mathrm{m}^{-1}\right), W$ is undulation exponent, and the undulation exponents are given with values in the range from 1.8 to 3.3 .

The general expression for the relationship between the vehicle speed $V(\mathrm{~m} / \mathrm{s})$, the spatial frequency $f(\mathrm{~Hz})$, and the temporal frequency $G_{q}(f)\left(\mathrm{m}^{2} / \mathrm{Hz}\right)$ are presented in

$$
\begin{gathered}
f=V \cdot n, \\
G_{q}(f)=\frac{1}{V} \cdot G_{q}(n)=G_{q}\left(n_{0}\right) \cdot n_{0}^{W} \cdot \frac{V^{W-1}}{f^{W}} .
\end{gathered}
$$

Taking statistical analysis of the road surface into account, the spatial frequency $n$ ranges from 0.011 to $2.83 \mathrm{~m}^{-1}$, at the commonly speed $(10-30 \mathrm{~m} / \mathrm{s})$, it can guarantee the temporal frequency $f$ ranges from 0.33 to $28.3 \mathrm{~Hz}$, which considers the natural frequencies of the sprung mass and unsprung mass effectively.

\section{Single-Wheel Road Time Domain Model}

Discrete PSD in temporal frequency domain is required to simulate road surface in time domain, which can be obtained by

$$
\begin{aligned}
& G_{q}\left(f_{k}\right) \\
& \quad= \begin{cases}0, & k=1,2, \ldots, N_{l}, \\
G_{q}\left(n_{0}\right) n_{0}^{W} \frac{V^{W-1}}{f_{k}^{W},} & k=N_{l}+1, N_{l}+2, \ldots, N_{u}+1, \\
0, & k=N_{u}+2, N_{u}+3, \ldots, N,\end{cases}
\end{aligned}
$$

where $G_{q}\left(f_{k}\right)$ is the discrete PSD in temporal frequency domain, and $N_{l}$ is the lower limit of the spatial frequency, $N_{u}$ is the upper limit of the spatial frequency.

According to the Fourier transform, the relationship between the discrete PSD in temporal frequency domain 


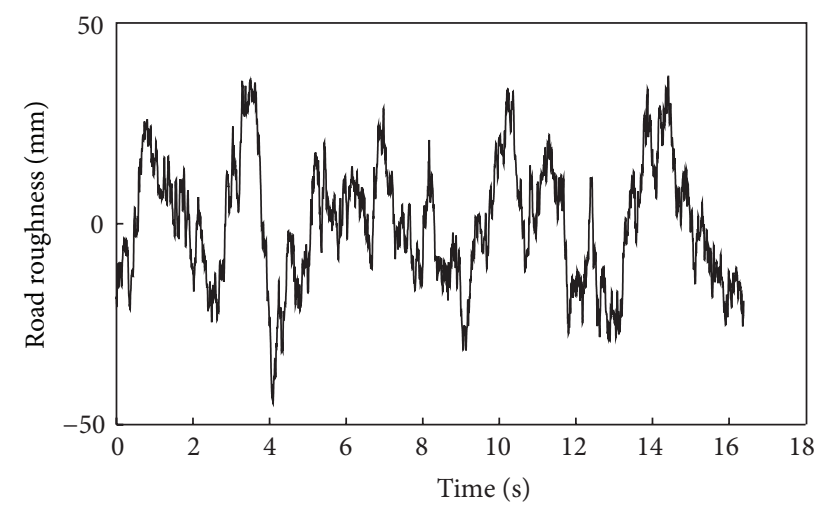

Figure 1: Single-wheel road surface time domain signal ( $C$-level $\mathrm{road}, 70 \mathrm{Km} / \mathrm{h}$ ).

and the corresponding spectral amplitude can be obtained as follows:

$$
\begin{gathered}
|Q(k)|=N \sqrt{\frac{\Delta f}{2} G_{q}\left(f_{k}\right),} \\
\Delta f=\frac{1}{T} \\
Q(k)=|Q(k)| \cdot e^{j \phi_{k}},
\end{gathered}
$$

where $Q(k)$ is the road random excitation spectrum, $T$ is the sampling time, $|Q(k)|$ is the corresponding spectral amplitude, $j$ is the imaginary unit, and $\phi_{k}$ is a uniformly distributed random variable ranged from 0 to $2 \pi, k=$ $1,2, \ldots, N$.

Then, road roughness random excitation signal can be obtained by the inverse Fourier transform of the complex sequences $Q(k)(k=1,2,3, \ldots, N)$ :

$$
x(n)=\frac{1}{N} \sum_{k=1}^{N} Q(k) e^{j(2 \pi / N) n k}, \quad k=1,2, \ldots, N .
$$

A single-wheel $C$-level road surface time domain signal is shown in Figure 1, in which the vehicle speed is $70 \mathrm{~km} / \mathrm{h}$. A comparison of the road PSD simulated with the ISO 8608 standard is shown in Figure 2, which shows that the road PSD simulated can match the ISO C-level road very well. In a word, the inverse Fourier transform method for a singlewheel road time domain model is accurate.

\section{Four-Wheel Road Time Domain Model}

A four-wheel vehicle is subjected to excitations due to road roughness on the left and right wheel paths. Hence, to describe the excitations we need a stochastic model of parallel road tracks. The model should describe the variation within each track and the covariation between the tracks [23]. A four-wheel road time domain model is usually generated based on the correlation of the four-wheel road input, in which there is a time delay between the front and rear axle and the space is correlated between the left and right wheels.

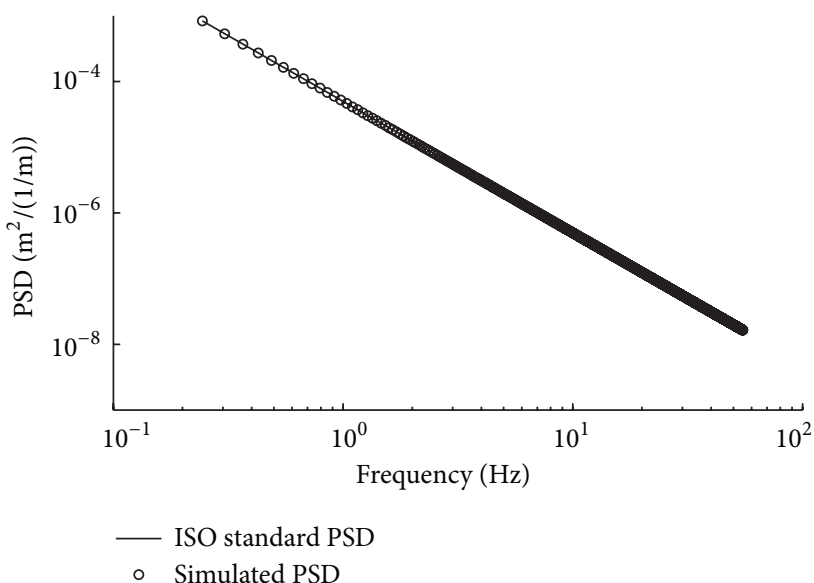

FIGURE 2: Comparison of the road PSD simulated with the ISO 8608 standard.

And, a four-wheel road surface domain model is established based on the following two assumptions.

(1) The wheel tracks of the vehicle front axle and rear axle are equal, and the vehicle keeps in a straight line with a constant speed.

(2) The statistical properties of the road profiles at left and right tires are the same, in other words, the autopower spectral density of the road profiles at left and right tires is the same and equal to the standard.

While the left and right tracks are usually statistically equivalent, the actual profiles are not identical. Generally, the difference between the left and right tracks brings a roll disturbance. However, the information regarding this roll disturbance is not included in the PSD of the individual wheel paths. Hence, in addition to the PSD, it is appropriate to study the coherence function. The statistical properties of road roughness between the left and right wheels are usually described by a cross-power spectral density function or a coherence function [24-26]. Surprisingly, the coherence functions of all roads (smooth motorways, main roads, paved country roads, gravel roads, etc.) are very similar [27]. And the coherence function is described by

$$
\operatorname{coh}(n)=\frac{\left|G_{x y}(n)\right|}{\sqrt{G_{x x}(n) \cdot G_{y y}(n)}}
$$

where $G_{x x}(n)$ and $G_{y y}(n)$ are the auto-spectral densities of the individual tracks $\left(\mathrm{m}^{2} / \mathrm{m}^{-1}\right)$, and $G_{x y}(n)$ is the associated cross-spectral density $\left(\mathrm{m}^{2} / \mathrm{m}^{-1}\right), B$ is the wheel track $(\mathrm{m})$, and $n$ is the spatial frequency $\left(\mathrm{m}^{-1}\right)$.

The measurement data yield a coherence function which drops from a high value at $n=0$ to a very small value at high-frequency band [28], and the range is from 0 to 1 . When $\operatorname{coh}(n)=0$, the left- and right-wheel road roughness is completely uncorrelated, while the left- and right-wheel road roughness is perfectly correlated if $\operatorname{coh}(n)=1$. Robson [29] pointed out that the coherence function depends on the 


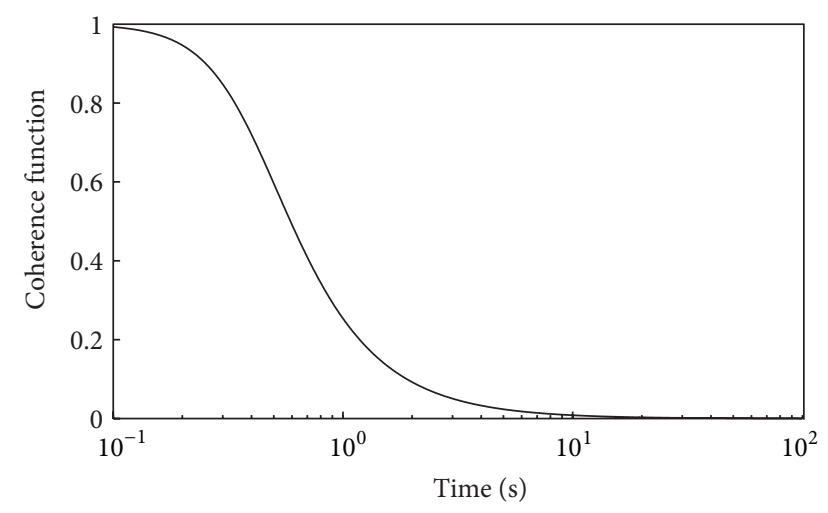

Figure 3: The coherence function of the left and right track under $C$-level road.

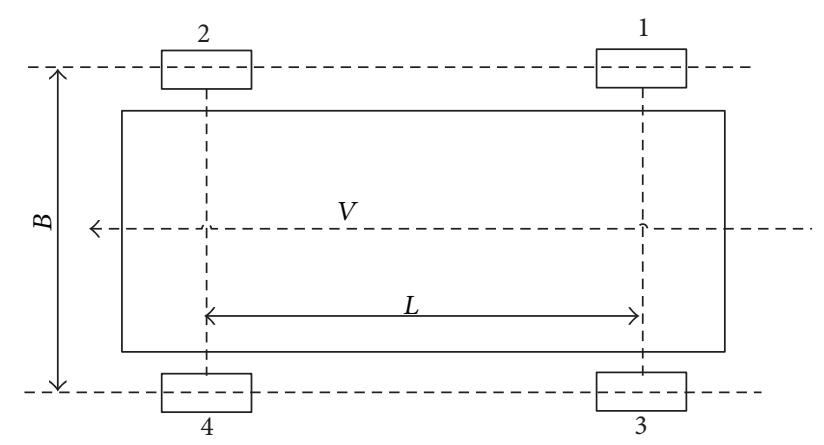

FIGURE 4: A top view of four-wheel vehicle.

wheel track and spatial frequency. The coherence function was described by Ammon [30] as

$$
\operatorname{coh}(n, B)=\left[1+\left(\frac{n B^{\varepsilon}}{n_{q}}\right)^{\partial}\right]^{-q},
$$

where the inflection point and the slope of the inflection point are determined by the parameters $n_{q}$ and $q$, which can be fitted by experimental data. $\varepsilon$ is the density of the coherence function between different tracks and $\partial$ is the frequency index. The coherence function of the left and right tracks under $C$-level road is shown in Figure 3.
Previously the single-wheel road time domain model and coherence function have been introduced, then a four-wheel road time domain model will be discussed as follows. A top view of four-wheel vehicle is shown in Figure 4, and the spectrum matrix of four-wheel road input is described in

$$
\begin{aligned}
{\left[G_{q}(f)\right] } & =\left[\begin{array}{llll}
G_{11} & G_{12} & G_{13} & G_{14} \\
G_{21} & G_{22} & G_{23} & G_{24} \\
G_{31} & G_{32} & G_{33} & G_{34} \\
G_{41} & G_{42} & G_{43} & G_{44}
\end{array}\right] \\
& =\left[\begin{array}{cccc}
G_{11} & G_{11} e^{-j 2 \pi f \tau} & G_{13} & G_{13} e^{-j 2 \pi f \tau} \\
G_{11} e^{j 2 \pi f \tau} & G_{11} & G_{13} e^{j 2 \pi f \tau} & G_{13} \\
G_{13}^{*} & G_{13}^{*} e^{-j 2 \pi f \tau} & G_{33} & G_{33} e^{-j 2 \pi f \tau} \\
G_{13}^{*} e^{j 2 \pi f \tau} & G_{13}^{*} & G_{33} e^{j 2 \pi f \tau} & G_{33}
\end{array}\right],
\end{aligned}
$$

where $G_{i j}(i \neq j)(i, j=1,2,3,4)$ is the cross-power spectral density, $G_{i j}(i=j)$ is the auto-power spectral density, $G_{i j}^{*}$ is the complex conjugate matrix of $G_{i j}$, and $\tau$ is the time delay of front- and rear-wheel road input, which can be expressed as

$$
\tau=\frac{L}{V},
$$

where $L$ is the wheelbase $(\mathrm{m})$ and $V$ is the vehicle speed $(\mathrm{m} / \mathrm{s})$. $G_{13}(f)$ can be obtained by

$$
\begin{aligned}
G_{13}(f) & =\left|G_{13}(f)\right| e^{j \phi_{13}(f)} \\
& =\sqrt{G_{11}(f) \cdot G_{33}(f)} \cdot \operatorname{coh}(f) \cdot e^{j \phi_{13}(f)},
\end{aligned}
$$

where $\phi_{13}(f)$ is the phase difference of road PSD of the leftand right-front wheel. According to measured pavements, the phase differences of road PSD of the left- and rightfront wheel are approximately 0; at this point, the impacts on vehicle performance are negligible; thus, it is assumed that $\phi_{13}(f)=0$ in this paper. Therefore, (11) and (9) can be rewritten as

$$
\begin{gathered}
G_{13}(f)=\left|G_{13}(f)\right| e^{j \phi_{13}(f)}=\sqrt{G_{11}(f) \cdot G_{33}(f)} \cdot \operatorname{coh}(f) \\
{\left[G_{q}(f)\right]=G_{q}(f)\left[\begin{array}{cccc}
1 & e^{-j 2 \pi f \tau} & \operatorname{coh}(f) & \operatorname{coh}(f) e^{-j 2 \pi f \tau} \\
e^{j 2 \pi f \tau} & 1 & \operatorname{coh}(f) e^{j 2 \pi f \tau} & \operatorname{coh}(f) \\
\operatorname{coh}(f) & \operatorname{coh}(f) e^{-j 2 \pi f \tau} & 1 & e^{-j 2 \pi f \tau} \\
\operatorname{coh}(f) e^{j 2 \pi f \tau} & \operatorname{coh}(f) & e^{j 2 \pi f \tau} & 1
\end{array}\right] .}
\end{gathered}
$$

Then, the road spectrum relationship between the left and right wheels can be obtained as follows:

$$
Q_{3}(f)=Q_{1}(f) \operatorname{coh}(f) .
$$

And the road spectrum relationship between the front and rear wheels can be obtained as follows:

$$
Q_{2}(f)=Q_{1}(f) e^{-j 2 \pi f \tau} .
$$




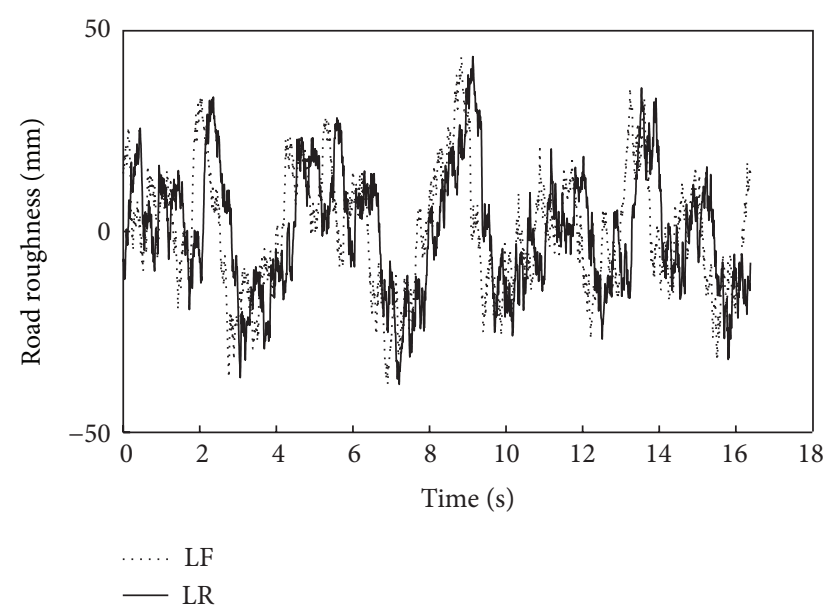

FIGURE 5: Comparison of left-front wheel (LF) with left-rear wheel (LR) time domain signal.

So far a four-wheel time domain model can be obtained via the following steps.

(1) Road roughness level $G_{q}\left(n_{0}\right)$, the vehicle speed $V$, the coherence function $\operatorname{coh}(f)$, the lower limit of the spatial frequency $N_{l}$, and the upper limit of the spatial frequency $N_{u}$ are known as initial conditions.

(2) The spectrum of left-front wheel road roughness $Q_{1}(k)$ can be obtained analogous to the method of generating single-wheel road random excitation spectrum.

(3) The road random excitation spectrum of other wheels $Q_{2}(k)$ and $Q_{4}(k)$ can be obtained from (15)-(17), and there is a time delay between the left-front road input $Q_{1}(k)$ and the left-rear road input $Q_{3}(k)$. The $Q_{2}(k)$ and $Q_{4}(k)$ are obtained via a coherence function between the left and right wheels:

$$
\begin{gathered}
Q_{2}(k)=Q_{1}(k) e^{-j 2 \pi f_{k} \tau}, \\
Q_{3}(k)=Q_{1}(k) \operatorname{coh}(k), \\
Q_{4}(k)=Q_{3}(k) e^{-j 2 \pi f_{k} \tau}=Q_{1}(k) \operatorname{coh}(k) e^{-j 2 \pi f_{k} \tau} .
\end{gathered}
$$

(4) The corresponding road roughness random excitation signals can be obtained by the inverse Fourier transform of the complex sequences $Q_{i}(k)(i=$ $1,2,3,4)$,

$$
x_{i}(n)=\frac{1}{N} \sum_{k=1}^{N} Q_{i}(k) e^{j(2 \pi / N) n k}, \quad n=1,2, \ldots, N .
$$

\section{Simulation Results}

The results indicated in this section include the simulation of the road surfaces discussed in the previous section. And a four-wheel road surface time domain signal for a class $C$ random road at the speed of $70 \mathrm{Km} / \mathrm{h}$ is shown in Figures 57.

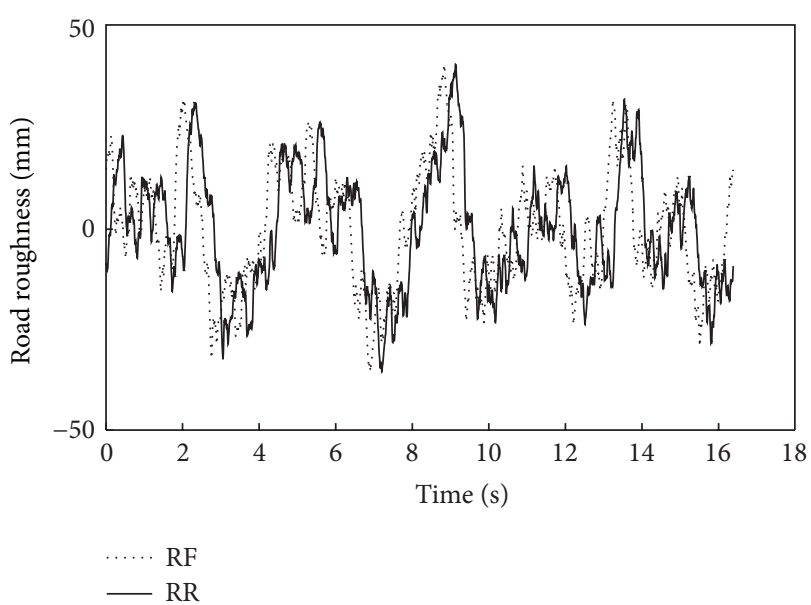

FIGURE 6: Comparison of right-front wheel (RF) with right-rear wheel (RR) time domain signal.

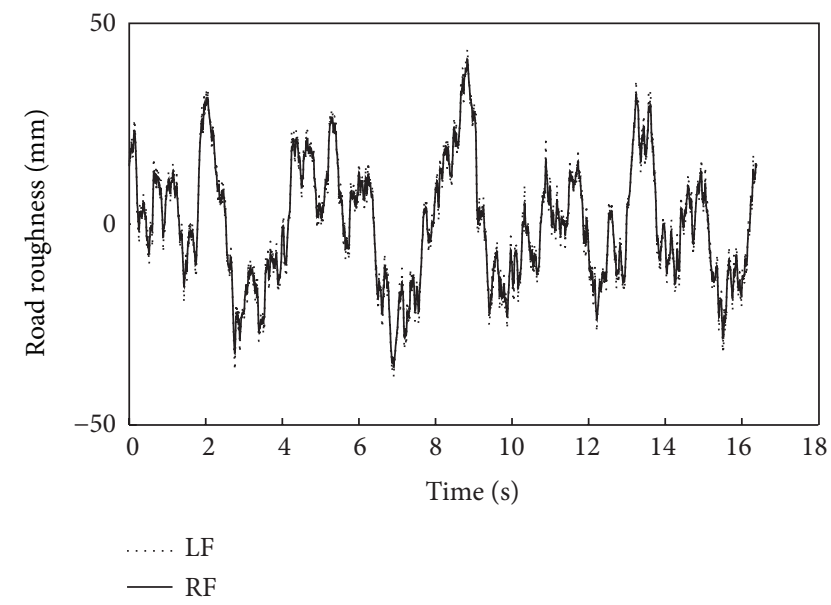

FIGURE 7: Comparison of left-front wheel (LF) with right-front wheel (RF) time domain signal.

Figure 5 shows a comparison of the road time domain signal between the left-front wheel (LF) and the left-rear wheel (LR), and the comparison of the road time domain signal between the right-front wheel (RF) and the rightrear wheel (RR) is shown in Figure 6. It can be found obviously that there is time delay between front-wheel and rear-wheel time domain signals, which is exactly equal to the $L / V$ (see (10)). Figure 8 is a comparison of the road PSDs simulated with the ISO 8608 standards. Figures 8(a) and 8(c) demonstrate that the road PSD of the front and rear wheels is consistent with the ISO 8608 standard values, which proves that the Inverse Fourier Transform is accurate to generate the front- and rear-wheel time domain signals. However, from Figure 7, we can see that the amplitude of right-front wheel (RF) is smaller than left-front wheel (LF) time domain signal; simultaneously, there is a deviation $\Delta G_{q}(f)$ between the road PSD of the left and right wheels from the beginning of midfrequency band in Figures 8(b) and 8(d), and the deviation increases with the frequency increasing. In other words, the road PSD of the right wheel is smaller than the 


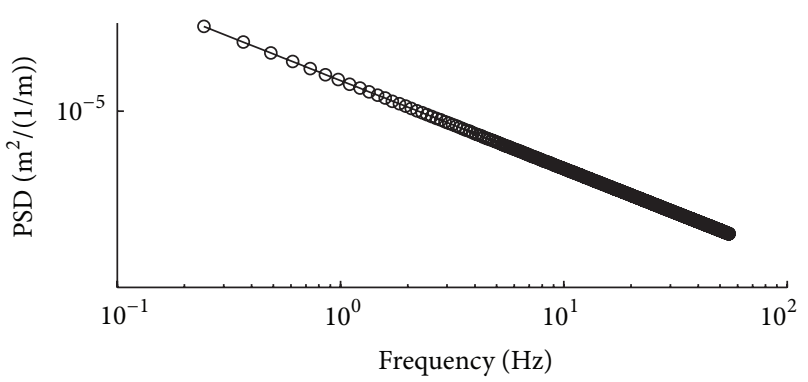

(a) Left-front wheel

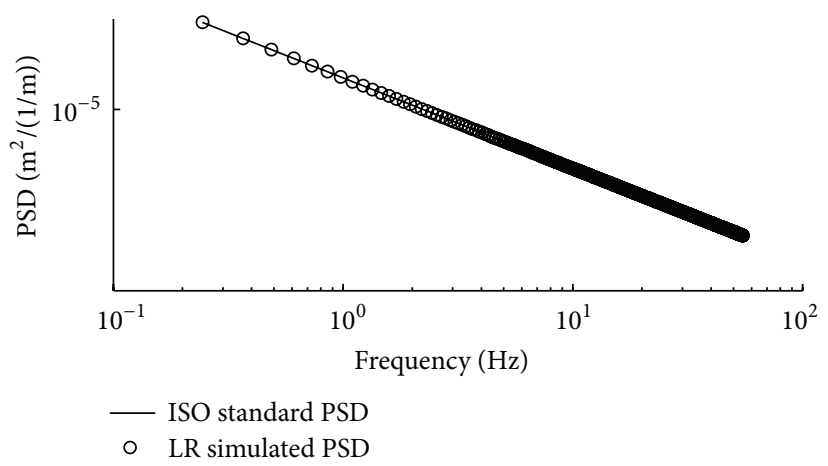

(c) Left-rear wheel

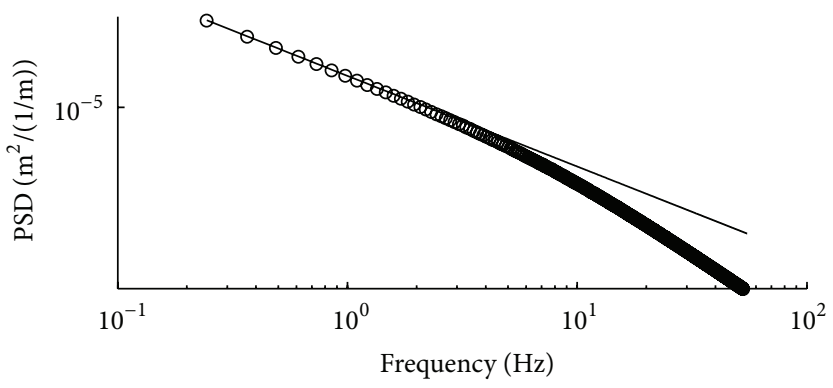

(b) Right-front wheel

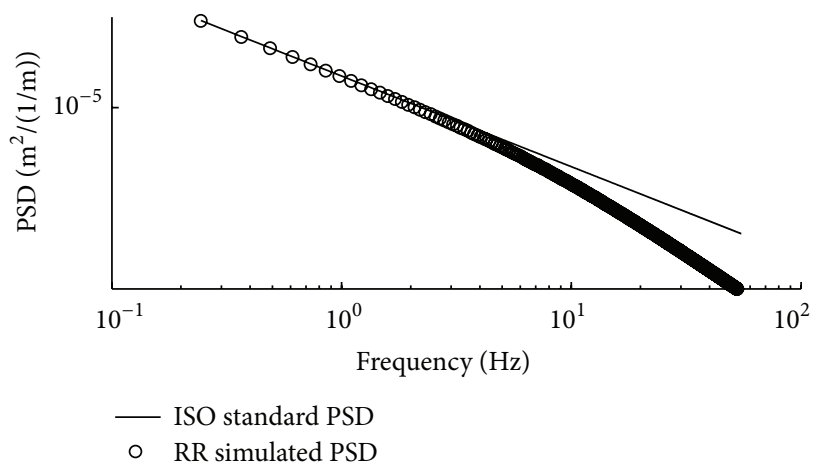

(d) Right-rear wheel

FIGURE 8: Comparison of the road PSDs simulated with the ISO 8608 standards.

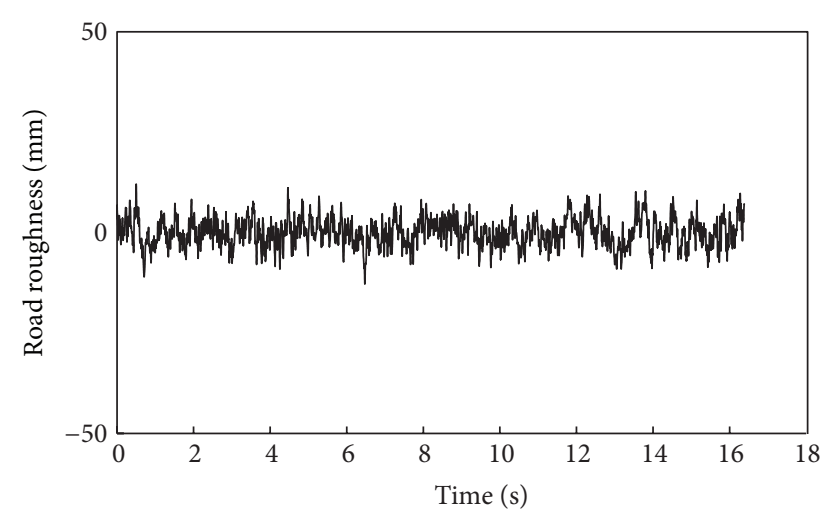

Figure 9: The smaller time domain signal generated based on the deviation $\Delta G_{q}(f)$.

road PSD of the left wheel on the same axle that is consistent with the ISO 8608 standard value, which can be described by

$$
\Delta G_{q}(f)=G_{q}(f)-G_{q \operatorname{simu}}(f)
$$

where $G_{q}(f)$ is the standard PSD values, $G_{q \text { simu }}(f)$ is the simulated PSD values, and $\Delta G_{q}(f)$ is the deviation between the road PSD of the left wheel (consistent with the standard) and right wheel.

In addition, the right-wheel time domain signal cannot be obtained when $\operatorname{coh}(f)$ is 0 , which only considers the correlation of the left- and right-wheel road roughness, while ignoring the uncorrelation of the left- and right-wheel road roughness. Since the value of coherence function is between
0 and 1 and it is near 0 at high-frequency band, according to (16) and (17), it can be found that the reasons for the deviation are mainly from the coherence function. Hence, the compensation of the right-wheel time domain signal will be presented in the sequel.

\section{Correction of Four-Wheel Road Time Domain Model}

From the above, we know that there is a deviation $\Delta G_{q}(f)$ between the road PSD of left and right wheels since the uncorrelation of the left- and right-wheel road roughness is ignored. Hence, considering the uncorrelation of the left and right wheel road roughness, a new road spectrum relationship between the left and right wheels can be described by,

$$
Q_{3}^{\prime}(f)=Q_{1}(f) \operatorname{coh}(f)+\Delta Q(f),
$$

where, $\Delta Q(f)$ reflects the uncorrelation of the left- and rightwheel road roughness, which can be obtained by $\Delta G_{q}(f)$ based on (4) and (5). A compensation using time domain signal is generated via the inverse Fourier transform of $\Delta Q(f)$ by using new random sequence numbers, which is shown in Figure 9.

A new right-wheel time domain signal can be obtained by compensating the time domain deviation signal. A comparison of left-front wheel with right-front wheel time domaincompensated signal is shown in Figure 10, and it can be found that the amplitude of right-front wheel (RF) and left-front wheel (LR) time domain signals are the same approximately. 


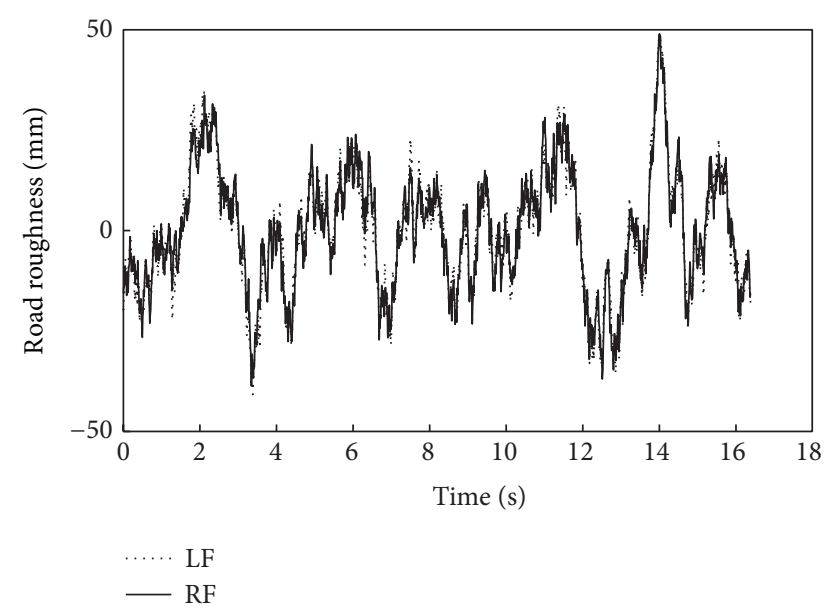

Figure 10: Comparison of left-front wheel (LF) with right-front wheel (RF) time domain signal after compensating.

Then, the new road PSDs of the four wheels can be obtained via Fourier transform, which is shown in Figure 11. It shows that the new road PSDs simulated can match ISO 8608 standards very well. In a word, this frequency compensation algorithm for a four-wheel road time domain model is accurate.

In addition, for the limit case, the method is also applicable. When $\operatorname{coh}(f)$ is 0 , the left- and right-wheel time domain signals are completely uncorrelated, and a comparison of leftfront wheel with left-rear wheel time domain signals is shown in Figure 12. It illustrates that the right-front wheel (RF) and left-front wheel (LR) time domain signals are completely uncorrelated, which correspond with the definition of the correlation function. Figure 13 shows the comparison of the road PSDs simulated with the ISO 8608 standards. Obviously, the new road PSDs simulated can match ISO 8608 standards very well.

When $\operatorname{coh}(f)$ is 1 , the left- and right-wheel road roughness are perfectly correlated, and a comparison of the leftfront wheel with the left-rear wheel time domain signals is shown in Figure 14. It illustrates that the right-front wheel (RF) and left-front wheel (LR) time domain signals are completely the same, which correspond with the definition of the correlation function. Figure 15 shows the comparison of the road PSDs simulated with the ISO 8608 standards. Obviously, the new road PSDs simulated can also match ISO 8608 standards very well. In summary, this frequency compensation algorithm for a four-wheel road time domain model is accurate.

The frequency compensation algorithm can also be used to correct the four-wheel surface time domain models generated by other methods when there is a deviation between the road PSDs simulated and the ISO 8608 standards.

\section{Analysis on Vehicle Dynamic Behavior}

Since the road surface irregularities are the main source of excitation to the vehicle system, to analyze the vehicle dynamic behavior more accurately, a suitable representation of these irregularities is required, which is shown in Figure 16.

A comparison of vehicle dynamic behavior w/o (with or without) compensation will be presented as follows. Firstly, a 7-DOF vertical vehicle model is shown in Figure 17, which considers the vertical motion, pitch and roll of the sprung mass, and the four vertical motions of four unsprung masses.

Each corner of the vehicle is identified with $\{i, j\}$ index, where $i=\{l, r\}$ holds for left/right and $j=\{f, r\}$ for front/rear. These corners (i.e., positions and velocities of the dynamical part) are described as

$$
\begin{aligned}
& z_{f l}=z-\alpha l_{f}+\beta w-z_{t f l}, \\
& z_{f r}=z-\alpha l_{f}-\beta w-z_{t f r}, \\
& z_{r l}=z+\alpha l_{r}+\beta w-z_{t r l}, \\
& z_{r r}=z+\alpha l_{r}-\beta w-z_{t r r}, \\
& \dot{z}_{f l}=\dot{z}-\dot{\alpha} l_{f}+\dot{\beta} w-\dot{z}_{t f l}, \\
& \dot{z}_{f r}=\dot{z}-\dot{\alpha} l_{f}-\dot{\beta} w-\dot{z}_{t f r}, \\
& \dot{z}_{r l}=\dot{z}+\dot{\alpha} l_{r}+\dot{\beta} w-\dot{z}_{t r l}, \\
& \dot{z}_{r r}=\dot{z}+\dot{\alpha} l_{r}-\dot{\beta} w-\dot{z}_{t r r},
\end{aligned}
$$

where $z$ is the center of the sprung mass, $\alpha$ (resp. $\beta$ ) is the pitch (resp. roll) angle of the sprung mass around $y$-axis (resp. $x$-axis) at the center of sprung mass. $l_{f}, l_{r}$, and $w$ define the vehicle geometrical properties (as shown in Figure 17).

The full vehicle model, as depicted on Figure 17, is given by the following motion equations:

$$
\begin{gathered}
m_{t f l} \ddot{z}_{t f l}+k_{t f l}\left(z_{t f l}-z_{f l}\right)-F_{s f l}-F_{d f l}=0, \\
m_{t f r} \ddot{z}_{t f r}+k_{t f r}\left(z_{t f r}-z_{f r}\right)-F_{s f r}-F_{d f r}=0, \\
m_{t r l} \ddot{z}_{t r l}+k_{t r l}\left(z_{t r l}-z_{r l}\right)-F_{s r l}-F_{d r l}=0, \\
m_{t r r} \ddot{z}_{t r r}+k_{t r r}\left(z_{t r r}-z_{r r}\right)-F_{s r r}-F_{d r r}=0, \\
\sum m \ddot{z}+F_{s i j}+F_{d i j}=0, \\
\sum I_{\alpha} \ddot{\alpha}-F_{s f j} l_{f}+F_{s r j} l_{r}-F_{d f j} l_{f}+F_{d r j} l_{r}=0, \\
\sum I_{\beta} \ddot{\beta}+w F_{s i l}-w F_{s i r}+w F_{d i l}-w F_{d i r}=0,
\end{gathered}
$$

where $m$ and $m_{t i j}$ denote the sprung and unsprung mass, respectively. The moment of inertia about the $x$-axis (resp. $y$ axis) of the vehicle sprung mass is denoted as $I_{\beta}$ (resp. $I_{\alpha}$ ). $F_{s i j}$ and $F_{d i j}$ are spring force and damper force, respectively, which can be described by

$$
F_{s i j}=k_{s i j} z_{i j}, \quad F_{d i j}=c_{i j} \dot{z}_{i j},
$$

where $k_{s i j}$ and $c_{i j}$ are spring stiffness and damping coefficient, respectively.

Then, the full vehicle model can be established by Matlab/Simulink, and the outputs include the weighted RMS 


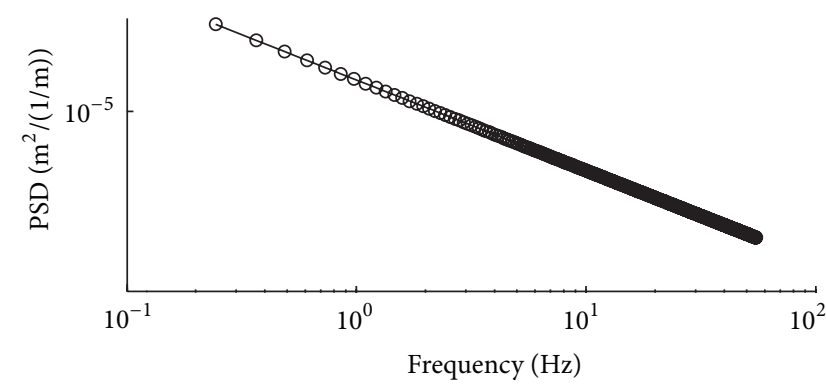

(a) Left-front wheel

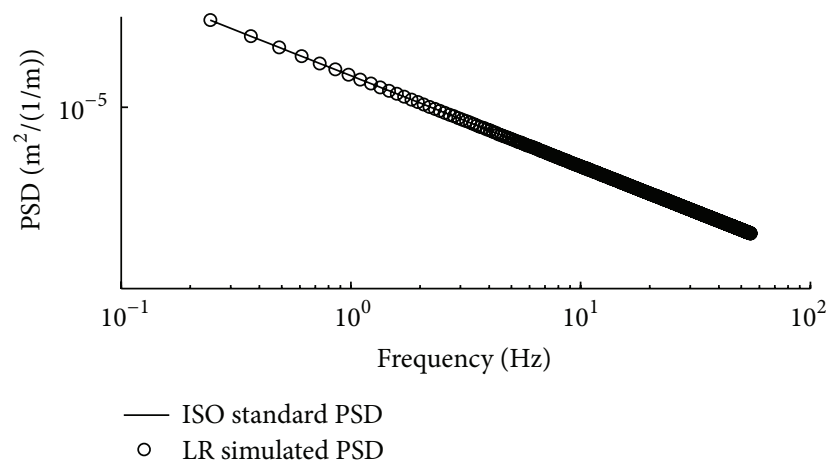

(c) Left-rear wheel

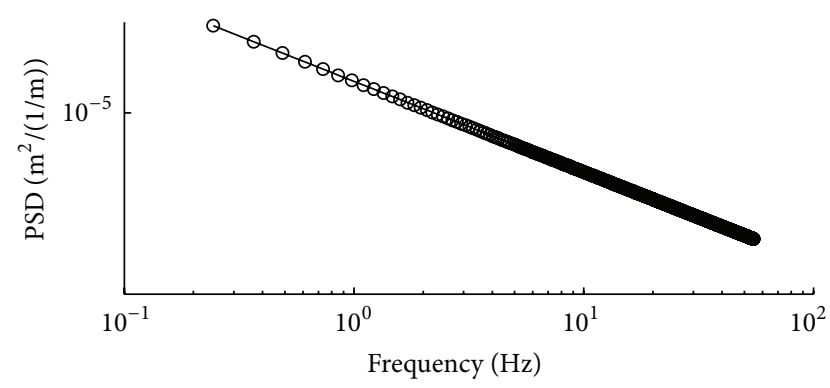

(b) Right-front wheel

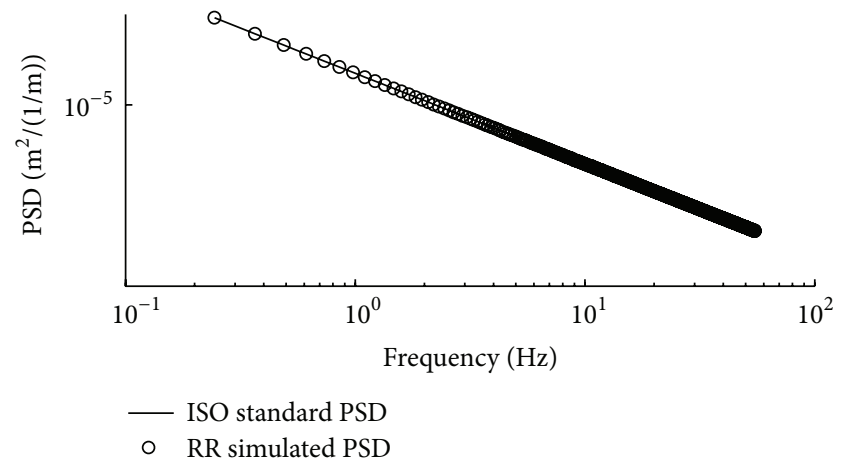

(d) Right-rear wheel

FIGURE 11: Comparison of the new road PSDs of the four wheels simulated with the ISO 8608 standards.

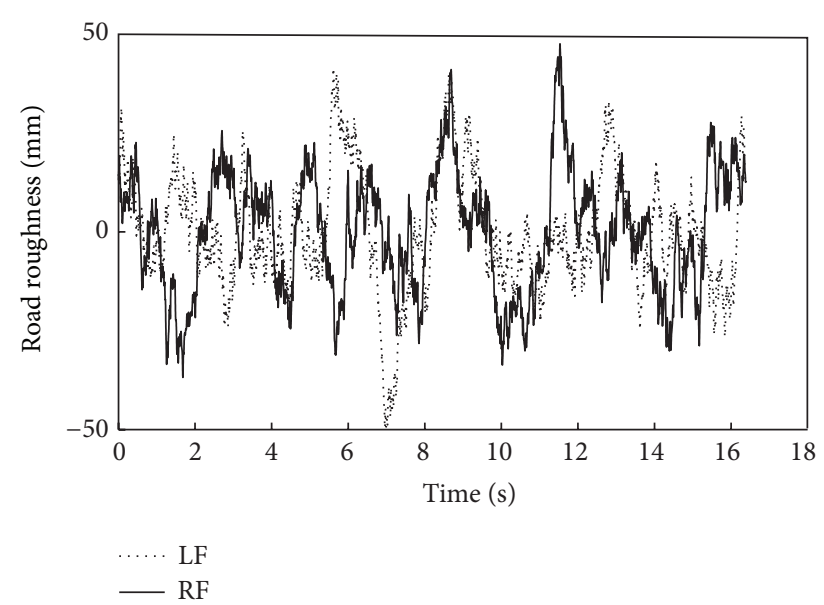

FIGURE 12: Comparison of left-front wheel (LF) with left-rear wheel (LR) time domain signal when $\operatorname{coh}(f)$ is 0 .

(root mean square) of acceleration $\left(A c_{-}\right.$rms, $\mathrm{m} / \mathrm{s}^{2}$ ), the roll angle RMS ( $\beta \_$rms), the pitch angle RMS ( $\alpha \_$rms), and the tire vertical force RMS (Ft_FL_rms, Ft_FR_rms, Ft_RL_rms, Ft_RR_rms, N).

In this paper, the frequency compensation algorithm is installed in the road input for a sedan model to illustrate the sedan's behavior. The parameters of a $C$-class sedan are shown in Table 1. Simulation results run over a $C$-level road surface with the speed of $70 \mathrm{Km} / \mathrm{h}$ tabulated in Table 2 . And the frequency compensation algorithm can also be installed in the other vehicle runs on a random road.
TABLE 1: Parameters of the $C$-class sedan.

\begin{tabular}{lccc}
\hline Symbol & Description & Unit & Value \\
\hline$m$ & Vehicle sprung mass & $\mathrm{kg}$ & 2110 \\
$m_{f l}$ & Front/left unsprung mass & $\mathrm{kg}$ & 58.3 \\
$m_{f r}$ & Front/right unsprung mass & $\mathrm{kg}$ & 58.3 \\
$m_{r l}$ & Rear/left unsprung mass & $\mathrm{kg}$ & 63.3 \\
$m_{r r}$ & Rear/right unsprung mass & $\mathrm{kg}$ & 63.3 \\
$k_{t f l}$ & Front/left vertical tyre stiffness & $\mathrm{N} / \mathrm{m}$ & 235000 \\
$k_{t f r}$ & Front/right vertical tyre stiffness & $\mathrm{N} / \mathrm{m}$ & 235000 \\
$k_{t r l}$ & Rear/left vertical tyre stiffness & $\mathrm{N} / \mathrm{m}$ & 235000 \\
$k_{t r r}$ & Rear/right vertical tyre stiffness & $\mathrm{N} / \mathrm{m}$ & 235000 \\
$k_{s f l}$ & Front/left spring stiffness & $\mathrm{N} / \mathrm{m}$ & 27500 \\
$k_{s f r}$ & Front/right spring stiffness & $\mathrm{N} / \mathrm{m}$ & 27500 \\
$k_{s r l}$ & Rear/left spring stiffness & $\mathrm{N} / \mathrm{m}$ & 31300 \\
$k_{s r r}$ & Rear/right spring stiffness & $\mathrm{N} / \mathrm{m}$ & 31300 \\
$l_{f}$ & Distance between front-axle/c.o.g. G & $\mathrm{m}$ & 1.455 \\
$l_{r}$ & Distance between rear-axle/c.o.g. G & $\mathrm{m}$ & 1.515 \\
$w$ & Wheel track & $\mathrm{m}$ & 1.610 \\
$I_{\beta}$ & Sprung mass roll moment of inertia & $\mathrm{kg} \cdot \mathrm{m}^{2}$ & 710.1 \\
$I_{\alpha}$ & Sprung mass pitch moment of inertia & $\mathrm{kg} \cdot \mathrm{m}^{2}$ & 3668.5 \\
\hline & & &
\end{tabular}

In this analysis, the road input of left-front tire is set as a baseline, then the right-front road input is obtained via a coherence function w/o a compensation, and the rear road 


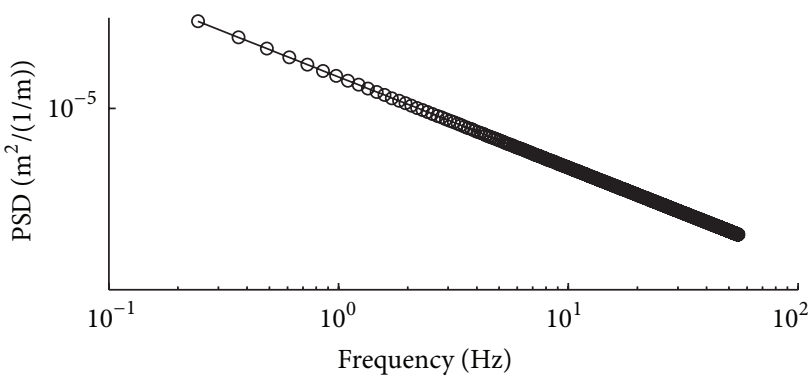

(a) Left-front wheel

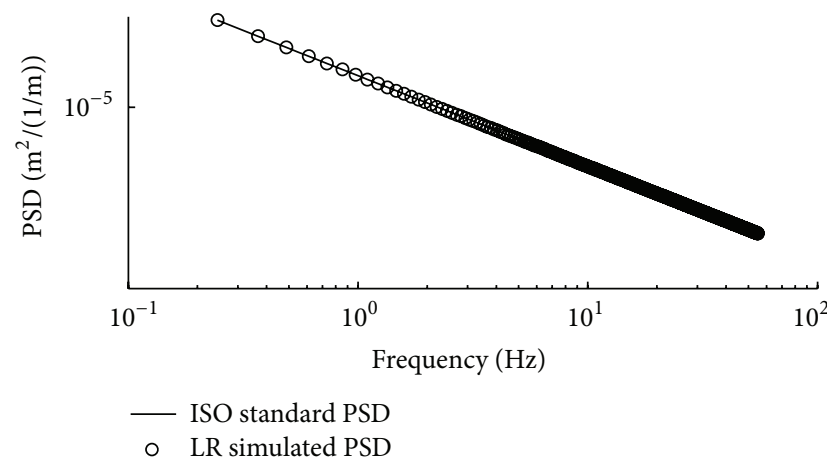

(c) Left-rear wheel

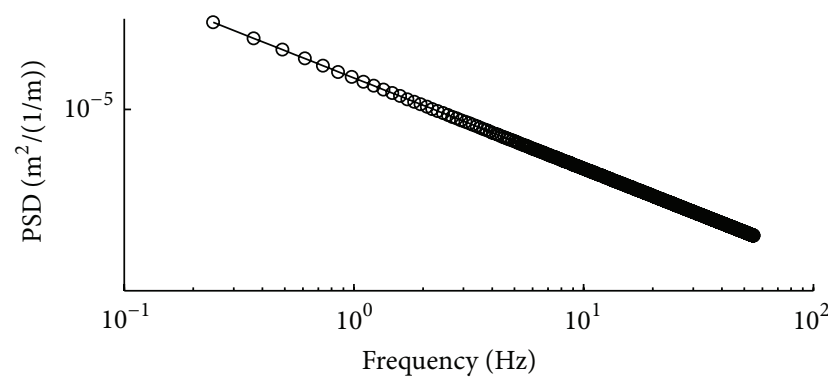

(b) Right-front wheel

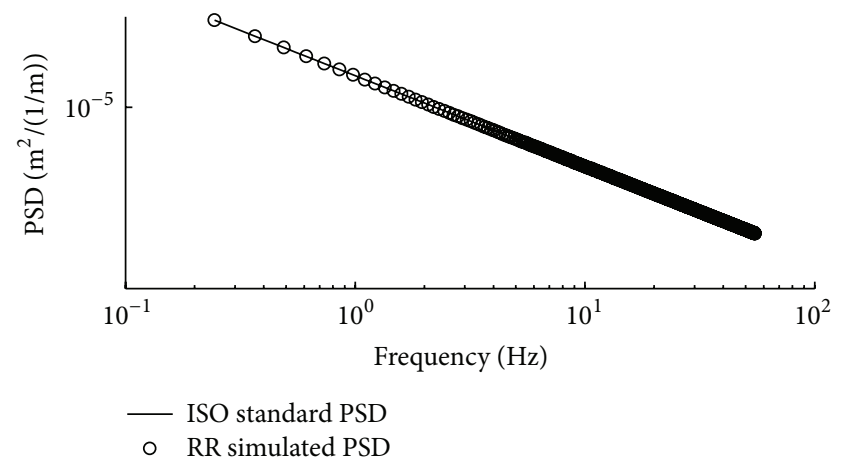

(d) Right-rear wheel

Figure 13: Comparison of the road PSDs simulated with the ISO 8608 standards when $\operatorname{coh}(f)$ is 0 .

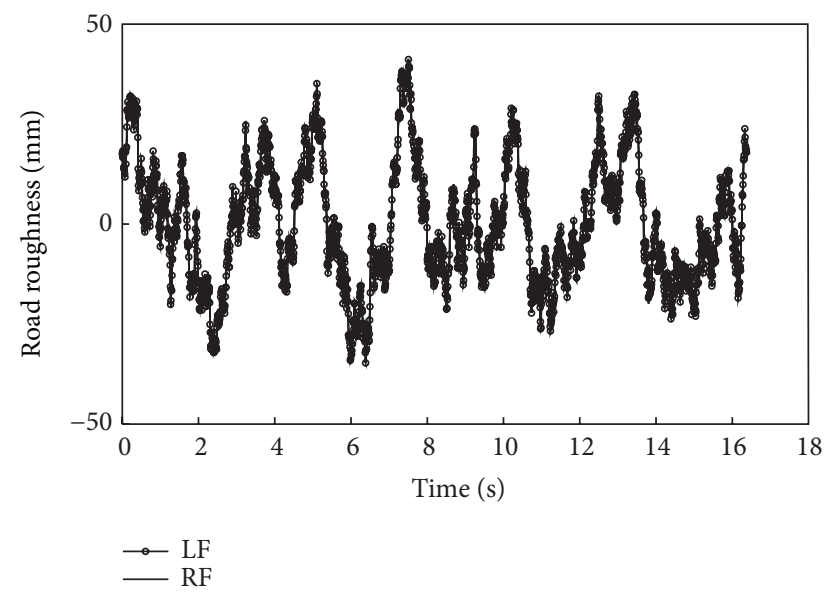

FIGURE 14: Comparison of left-front wheel (LF) with left-rear wheel (LR) time domain signal when $\operatorname{coh}(f)$ is 1 .

input has a time delay dependent on the wheel base and vehicle speed. Table 2 shows that the $\alpha \_$rms, Ft_FL_rms, and Ft_RL_rms without compensation are almost equal to the values with compensation since the PSDs of the left-side road input are the same, while the Ac_rms, $\beta_{-}$rms, Ft_FR_rms, and $F t \_R R_{-}$rms without compensation are significant smaller than the values with compensation, which is precisely caused by the previously mentioned deviation, since there is a deviation between the road PSDs of the two wheels on the same axle, which is the main reason that the acceleration RMS, the roll angle RMS, the RMS of tire vertical force of the right-front
TABLE 2: Simulation results.

\begin{tabular}{lccc}
\hline Results & Without compensation & With compensation & Difference \\
\hline Ac_rms & 0.3638 & 0.4081 & $10.8 \%$ \\
$\alpha \_r m s$ & 0.0062 & 0.0062 & 0 \\
$\beta$ _rms & $9.10 e-4$ & 0.0017 & $46.4 \%$ \\
Ft_FL_rms & $1.0115 e+3$ & $1.0162 e+3$ & $0.5 \%$ \\
Ft_FR_rms & $0.6824 e+3$ & $1.0100 e+3$ & $32.7 \%$ \\
Ft_RL_rms & $1.0514 e+3$ & $1.0566 e+3$ & $0.5 \%$ \\
Ft_RR_rms & $0.7190 e+3$ & $1.0534 e+3$ & $31.4 \%$ \\
\hline
\end{tabular}

and right-rear wheels without compensation are smaller than the values with compensation. Hence, the deviation of the PSD of the road input between two wheels on the same axle has an important influence on vehicle performances, which illustrates the importance of the frequency compensation algorithm proposed, which can be used for a control system installed in the vehicle to compensate road roughness for damper tuning in the future.

\section{Conclusions}

The road surface roughness has an important influence on ride comfort, ride safety, vehicle maneuverability, driver's and occupants' comfort, and vehicle dynamic load. In recent decades, random road models have been widely studied, and a four-wheel random road time domain model is usually generated based on the correlation of the four-wheel input, in 


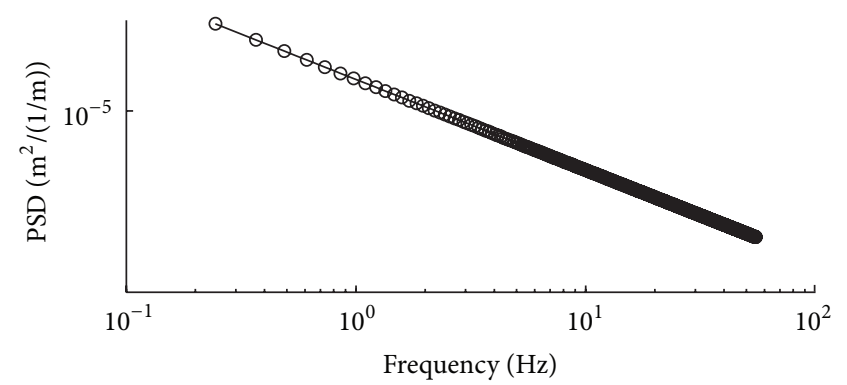

(a) Left-front wheel

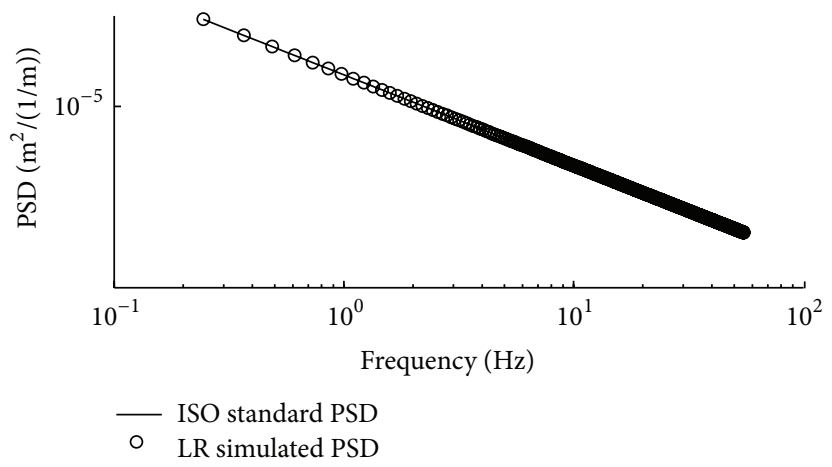

(c) Left-rear wheel

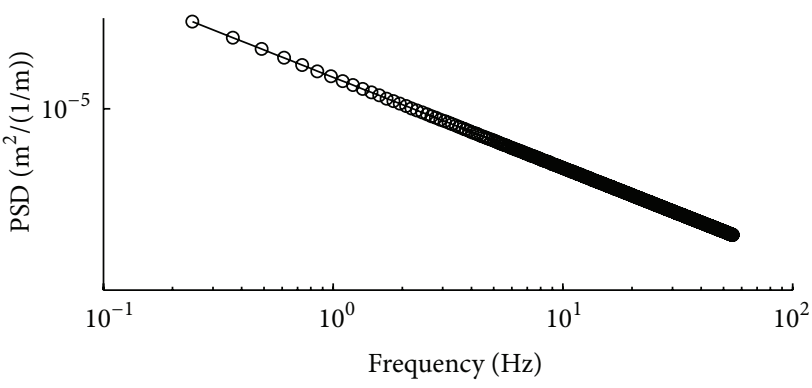

(b) Right-front wheel

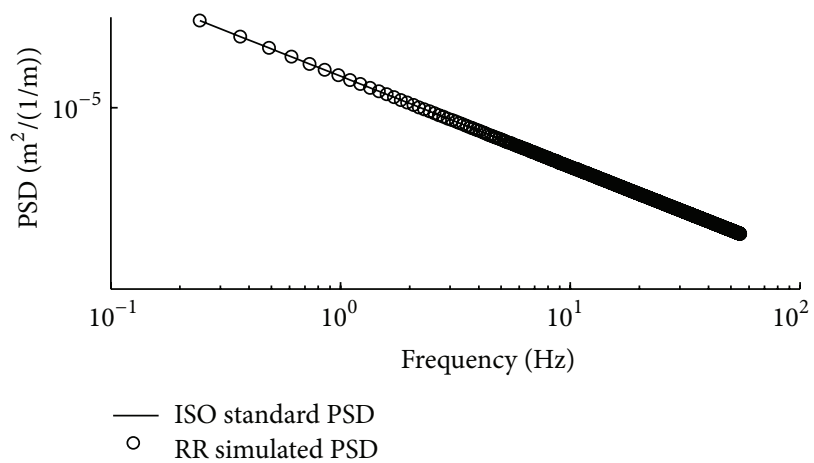

(d) Right-rear wheel

FIGURE 15: Comparison of the road PSDs simulated with the ISO 8608 standards when $\operatorname{coh}(f)$ is 1 .

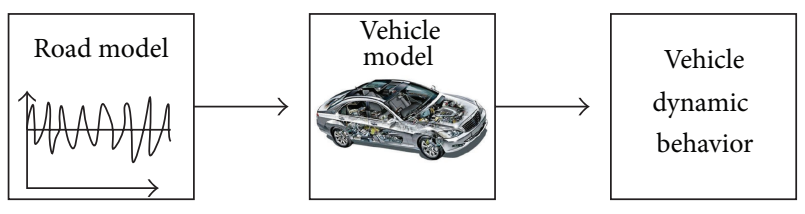

FIgURE 16: Analysis on the vehicle dynamic behavior.

which a coherence function is used to describe the coherence of the road input between the left and right wheels usually. Generally, the value of coherence function is between 0 and 1 , and it is near 0 at high-frequency band. As a result, the road roughness amplitude and the road PSD of one track will be smaller than the other one on the same axle; actually, it is caused by the uncorrelation between the left- and right-wheel road surface roughness. Hence, a frequency compensation algorithm is proposed to correct the deviation of the PSD of the road input between two wheels on the same axle, and it is installed in a 7-DOF vehicle dynamic study. The main conclusions can be drawn from the current study as follows.

(1) It is simple and accurate to generate a single-wheel time signal model by using the inverse Fourier transform method.

(2) With the Inverse Fourier Transform method via coherence function, the road PSDs of the front and rear wheels are consistent with the standard values; however, there is a deviation between the two-wheel road PSDs on the same axle. The coherence function value is between 0 and 1 , and it is near 0 at highfrequency band. As a result, the road roughness amplitude and the road PSD of one track will be smaller than the other one on the same axle.

(3) A road frequency compensation algorithm is proposed to correct the deviation of the two wheels road PSDs on the same axle, and it is installed in a road time domain model. The simulation results showed that the road PSDs with frequency compensation are consistent with the ISO 8608 standard values, which demonstrates that the proposed algorithm is correct, especially, for some limit case such as the left and right wheel road input are completely uncorrelated or perfectly correlated.

(4) The vehicle dynamic behavior with road frequency compensation show that the deviation compensation of two wheels on the same axle has an important influence on vehicle performances, which should be considered in the vehicle dynamic studies and the road frequency compensation can be used for a control system installed in the vehicle to compensate road roughness for damper tuning in the future.

\section{Acknowledgments}

Special thanks are due to the Open Research Fund Program of the State Key Laboratory of Advanced Design and Manufacturing for Vehicle Body (31115028), the China Postdoctoral Science Foundation (2012M520028), the National Natural Science Foundation of China (51205155), and the 


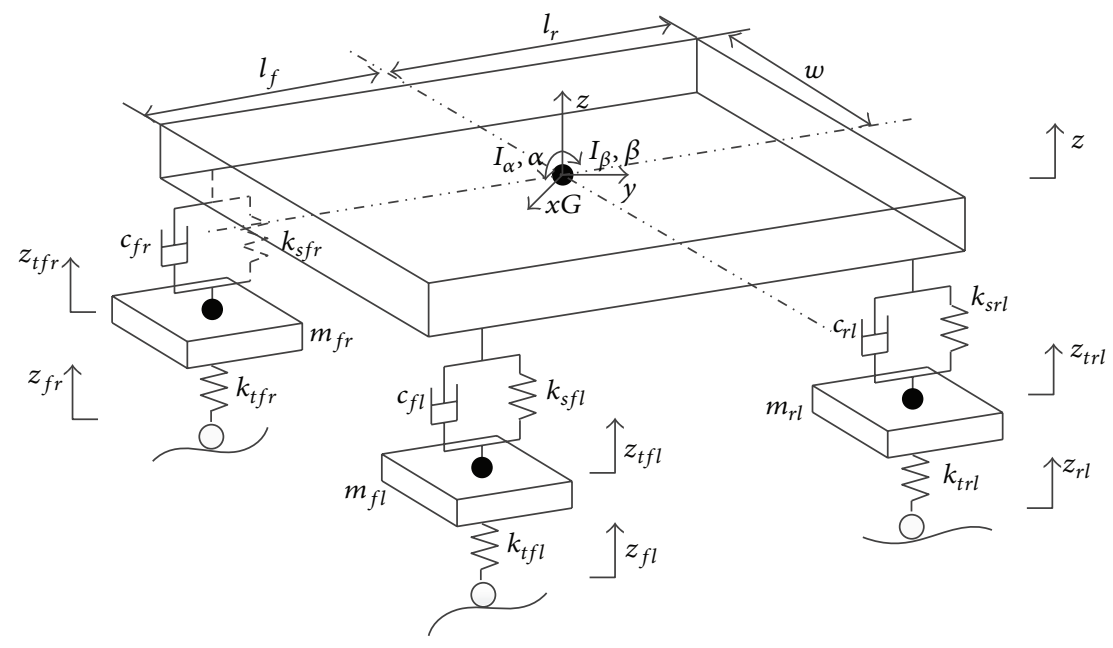

FIgURE 17: 7 DOF full vehicle model.

National Basic Research Program of China (973 Program) (2011CB711201) for supporting authors' research.

\section{References}

[1] P. Múčka, "Road waviness and the dynamic tyre force," International Journal of Vehicle Design, vol. 36, no. 2-3, pp. 216-232, 2004.

[2] Z. Yonglin and Z. Jiafan, "Numerical simulation of stochastic road process using white noise filtration," Mechanical Systems and Signal Processing, vol. 20, no. 2, pp. 363-372, 2006.

[3] K. Ahlin, J. Granlund, and F. Lindström, "Comparing road profiles with vehicle perceived roughness," International Journal of Vehicle Design, vol. 36, no. 2-3, pp. 270-286, 2004.

[4] S. M. Karamihas and M. W. Sayers, The Little Book of Profiling, University of Michigan, Ann Arbor, Mich, USA, 1998.

[5] M. Ambrož, G. Šušteršič, and I. Prebil, "Creating models of road sections and their use in driving dynamics simulations," Vehicle System Dynamics, vol. 45, no. 10, pp. 911-924, 2007.

[6] D. J. Whitehouse and J. F. Archard, "The properties of random surfaces of significance in their contact," Proceedings of the Royal Society of London A, vol. 316, pp. 97-121, 1970.

[7] M. Shinozuka and C.-M. Jan, "Digital simulation of random processes and its applications," Journal of Sound and Vibration, vol. 25 , no. 1, pp. 111-128, 1972.

[8] D. Cebon, Interaction between Heavy Vehicles and Roads, vol. 951, Society of Automotive Engineers, 1993.

[9] J.-J. Wu, "Simulation of rough surfaces with FFT," Tribology International, vol. 33, no. 1, pp. 47-58, 2000.

[10] M. Grigoriu, "On the spectral representation method in simulation," Probabilistic Engineering Mechanics, vol. 8, no. 2, pp. 75-90, 1993.

[11] ISO, Mechanical Vibration-Road Surface Profiles-Reporting of Measured Data, International Organization for Standardization, 1995.

[12] T. Yoshimura, "A semi-active suspension of passenger cars using fuzzy reasoning and the field testing," International Journal of Vehicle Design, vol. 19, no. 2, pp. 150-166, 1998.

[13] K. Bogsjö, "Evaluation of stochastic models of parallel road tracks," Probabilistic Engineering Mechanics, vol. 22, no. 4, pp. 362-370, 2007.
[14] A. Pazooki, S. Rakheja, and D. Cao, "Modeling and validation of off-road vehicle ride dynamics," Mechanical Systems and Signal Processing, vol. 28, pp. 679-695, 2012.

[15] R. Hassan and R. Evans, "Road roughness characteristics in car and truck wheel tracks," International Journal of Pavement Engineering, 2012.

[16] K. Bogsjö, K. Podgórski, and I. Rychlik, "Models for road surface roughness," Vehicle System Dynamics, vol. 50, no. 5, pp. 725-747, 2012.

[17] S. A. Hassan and O. S. Lashine, "Identification of road surface qualities for linear and non-linear vehicle modeling," in Proceedings of the 20th International Modal Analysis Conference (IMAC '02), pp. 318-323, Society for Experimental Mechanics, 2002.

[18] A. N. Heath, "Application of the isotropic road roughness assumption," Journal of Sound and Vibration, vol. 115, no. 1, pp. 131-144, 1987.

[19] A. N. Heath, "Evaluation of the isotropic road roughness assumption," Vehicle System Dynamics, vol. 17, supplement 1, pp. 157-160, 1988.

[20] D. Cebon and D. E. Newland, “The artificial generation of road surface topography by the inverse FFT method," Vehicle System Dynamics, vol. 12, no. 1-3, pp. 160-165, 1983.

[21] C. J. Dodds, "The laboratory simulation of vehicle service stress," Journal of Engineering for Industry, vol. 96, no. 2, pp. 391398, 1974.

[22] D. Cebon and D. E. Newlan, "The artificial generation of road surface topography by the inverse FFT method," in Proceedings of the 8th IAVSD-Symposium on the Dynamics of Vehicles on Roads and Tracks, pp. 29-42, Swets and Zeitlinger, Cambridge, Mass, USA, 1983.

[23] C. J. Dodds and J. D. Robson, "The description of road roughness," Journal of Sound and Vibration, vol. 31, no. 2, pp. 175-183, 1973.

[24] K. M. A. Kamash and J. D. Robson, "Implications of isotropy in random surfaces," Journal of Sound and Vibration, vol. 54, no. 1, pp. 131-145, 1977.

[25] K. M. A. Kamash and J. D. Robson, "The application of isotropy in road surface modelling," Journal of Sound and Vibration, vol. 57, no. 1, pp. 89-100, 1978. 
[26] G. C. Carter, "Coherence and time delay estimation," Proceedings of the IEEE, vol. 75, no. 2, pp. 236-255, 1987.

[27] K. Bogsjö, "Coherence of road roughness in left and right wheelpath," Vehicle System Dynamics, vol. 46, supplement 1, pp. 599609, 2008.

[28] R. Hongbin, C. Sizhong, and W. Zhicheng, "Model of excitation of random road profile in time domain for a vehicle with four wheels," in Proceedings of the International Conference on Mechatronic Science, Electric Engineering and Computer (MEC '11), pp. 2332-2335, Jilin, China, August 2011.

[29] J. D. Robson, "Road surface description and vehicle response," International Journal of Vehicle Design, vol. 1, no. 1, pp. 25-35, 1979.

[30] D. Ammon, "Problems in road surface modelling," Vehicle System Dynamics, vol. 20, pp. 28-41, 1992. 


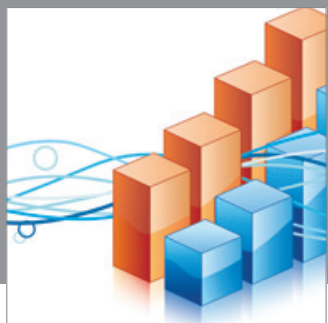

Advances in

Operations Research

mansans

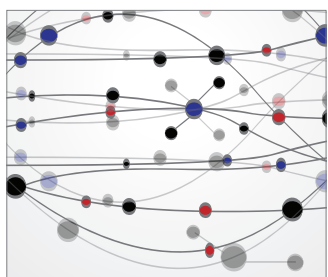

The Scientific World Journal
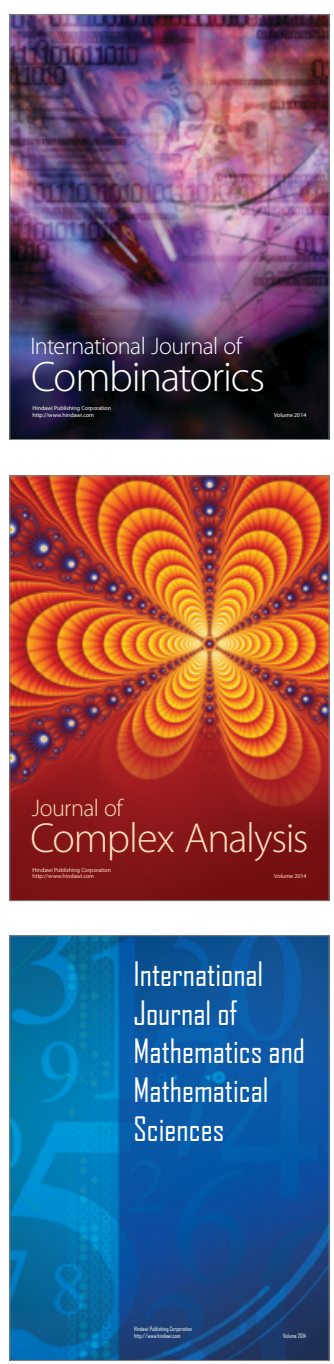
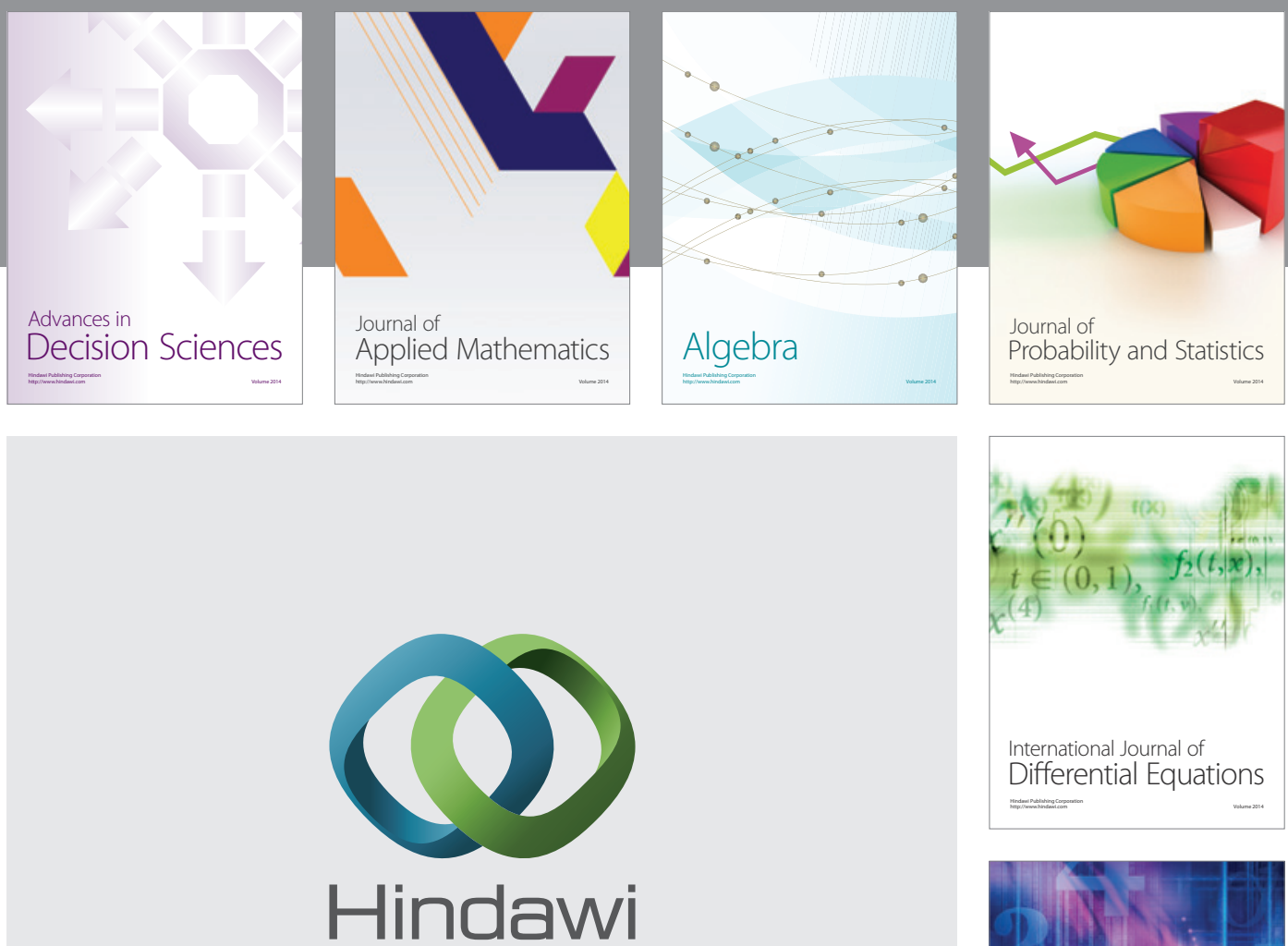

Submit your manuscripts at http://www.hindawi.com
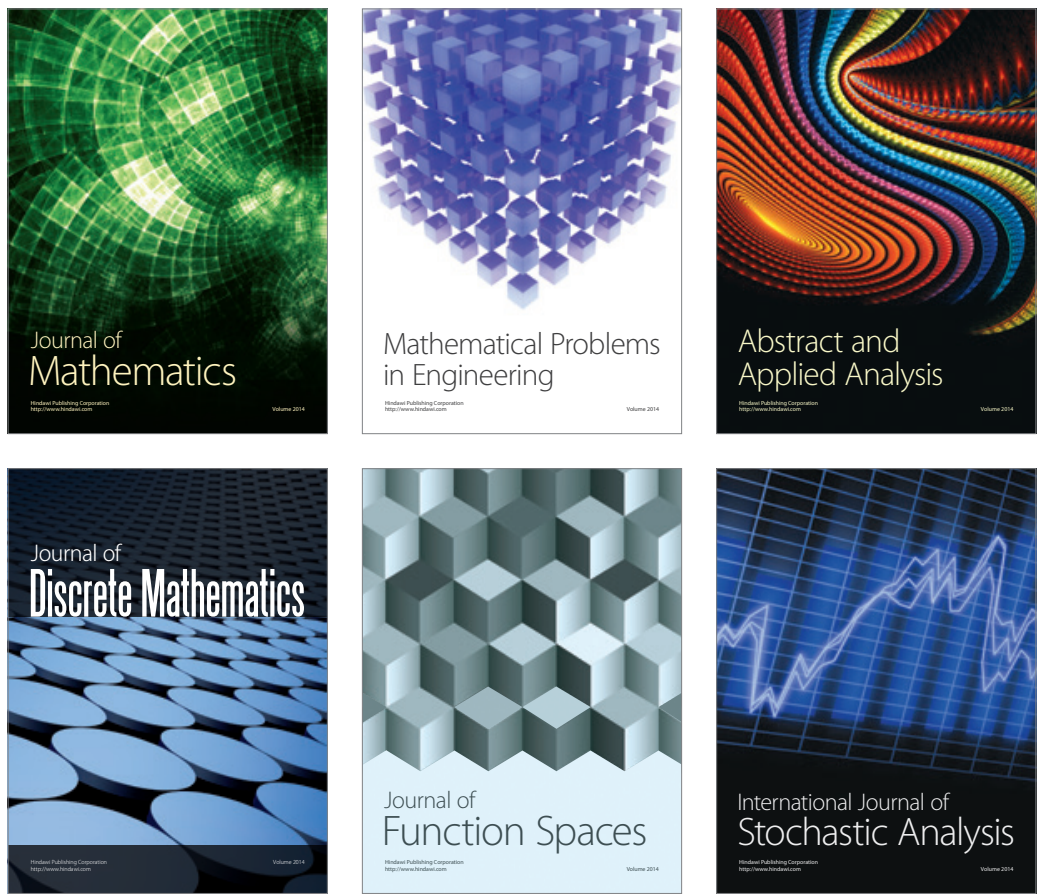

Journal of

Function Spaces

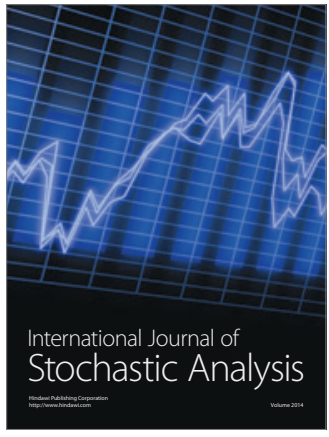

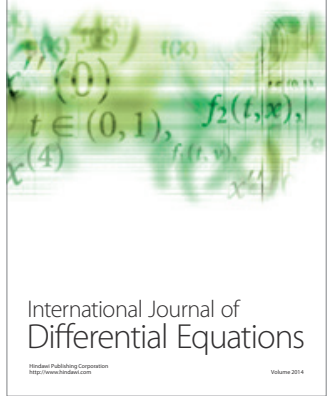
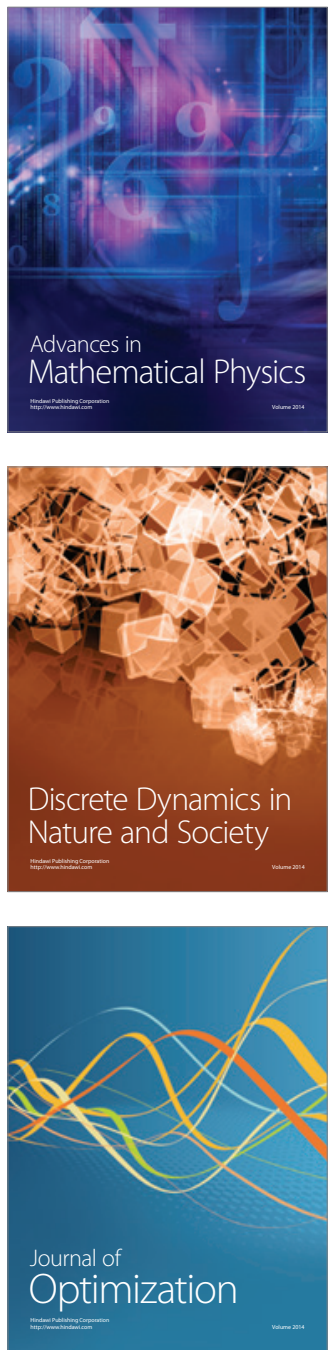